Pedagogía y Saberes n. ${ }^{\circ} 55$ Universidad Pedagógica Nacional

Facultad de Educación. 2021. pp. 137-154

\title{
Os saberes ou conhecimentos dos professores diante de atividades fundamentadas no ensino de ciências por investigação*
}

Teachers Knowledge in the Face of Activities Modeled through Inquiry-Based Science Teaching Los saberes o conocimientos de los profesores frente a las actividades fundamentadas en la enseñanza de las ciencias basadas en la investigación

\author{
João Paulo Camargo de Lima** \\ Tamires Bartazar Araujo*** \\ Marinez Meneghelo Passos****
}

Para citar este artículo

Camargo de Lima, J., Bartazar Araujo, T. y Meneghelo Passos, M. (2021). Os saberes ou conhecimentos dos professores diante de atividades fundamentadas no ensino de ciências por investigação. Pedagogía y Saberes, (55). https://doi. $\operatorname{org} / 10.17227 /$ pys.num55-11749

* $\quad$ Este artigo de investigação aqui apresentado é parte de resultados derivados da dissertação de mestrado de Tamires Bartazar Araújo, desenvolvida no âmbito do Programa de Pós-graduação em Ensino de Ciências, Humanas, e da Natureza da Universidade Tecnológica Federal do Paraná - Câmpus Londrina.

** Doutor em Física pela Universidade Federal de São Carlos, docente do Departamento Acadêmico de Física da Universidade Tecnológica Federal do Paraná (UTFPR) - Câmpus Londrina, e do programa de Pós-graduação em Ensino de Ciências Humanas, Sociais e da Natureza da UTFPR - Câmpus Londrina. Orcid: https://orcid.org/0000-0001-6847-8076.

*** Mestre em Ensino de Ciências Humanas, Sociais e da Natureza pela Universidade Tecnológica Federal do Paraná (UTFPR) - Câmpus Londrina, docente da Escola Municipal Olavo Soares Barros no município de Cambé. Atua na Secretaria Municipal de Educação do Município de Londrina na coordenação de educação de Jovens e Adultos, egressa do programa de Pós-graduação em Ensino de Ciências Humanas, Sociais e da Natureza da UTFPR - Câmpus Londrina. Orcid: https://orcid. org/0000-0002-9730-9762.

**** Doutora em Educação para a Ciência pela Universidade Estadual Paulista “Júlio de Mesquita Filho” (UNESP), docente sênior e docente do Programa de Pós-graduação em Ensino de Ciências e Educação Matemática da Universidade Estadual de Londrina (UEL) e Professora Colaboradora Sênior da Universidade Estadual do Norte do Paraná (UENP) - Câmpus Cornélio Procópio.

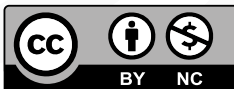




\title{
Resumo
}

A pesquisa, cujos resultados apresentamos neste artigo, assumiu o ensino de Ciências por investigação como estratégia de iniciação científica para estudantes e como conteúdo formativo para professores da Educação Básica. A questão que buscamos responder foi: de que maneira uma proposta de formação de professores para o ensino de Ciências por investigação pode promover a iniciação científica dos estudantes? Para tanto, consideramos três objetivos específicos: caracterizar a proposta de ensino de Ciências por investigação; discutir a formação de professores para o ensino de Ciências por investigação como estratégia de iniciação científica; apresentar contribuições de uma proposta para o desenvolvimento de sequências investigativas. Tomamos por pauta os encaminhamentos metodológicos da pesquisa qualitativa e realizamos entrevistas semiestruturadas para a coleta de dados, contando com a participação de dois professores de um município localizado na região norte do estado do Paraná, Brasil. Para a análise dos dados, utilizamos os procedimentos indicados pela Análise de Conteúdo e a descrição dos saberes ou conhecimentos de Shulman como categorias a priori. Dentre os principais resultados e discussões destacam-se os indícios das falas dos professores participantes, os quais mostram que o saber predominante em suas falas se refere ao saber pedagógico, seguido do conhecimento pedagógico do conteúdo e do conhecimento do conteúdo. Evidências de manifestações de mudança de pensamentos ou postura em relação às suas práticas pedagógicas também emergem de seus relatos. Outro resultado observado, diz respeito à aplicação da Proposta junto aos estudantes, o que evidenciou a promoção de momentos de iniciação científica.

\section{Palavras-chave}

ensino de Ciências por investigação; saberes ou conhecimentos docentes; formação de professores; iniciação científica

\begin{abstract}
The research results presented in this article took the investigation-based teaching Science as a scientific initiation strategy for students and as formative content for teachers of Basic Education. The question we sought to answer was: How can a proposal of teacher education for inquiry-based Science teaching promote scientific initiation for students? For that, we considered three specific objectives: to characterize the proposal of inquiry-based Science teaching, consider teachers' education for inquiry-based Science teaching as a strategy for scientific initiation and present contributions of the Proposal for the development of investigative sequences. The methodological guidelines of qualitative research and conduct semi-structured interviews for data collection will be used as our guideline, with the participation of two teachers from a municipal area located in the northern region of Paraná. For data analysis, we used the procedures indicated by Content Analysis and the description of Shulman's knowledge as priority categories. Among the main results and discussions, we highlight the evidence of participating teachers' speeches, which show that the predominant knowledge in their speeches refers to pedagogical knowledge, followed by pedagogical content knowledge and content knowledge. Evidence of manifestations of changing thoughts or posture concerning their pedagogical practices also emerges from their reports. Another observed result concerns the application of the Proposal to students, which evidenced the promotion of scientific initiation moments.
\end{abstract}

\section{Keywords}

inquiry-based science teaching; teachers knowledge; teacher education; scientific initiation

\section{Resumen}

La investigación, cuyos resultados presentamos en este artículo, asumió la enseñanza de las ciencias por medio de la investigación como una estrategia de iniciación científica para los estudiantes y como contenido formativo para los profesores de educación primaria y secundaria. La pregunta que buscábamos responder era: ¿cómo puede una propuesta de formación de profesores para la enseñanza de las ciencias por medio de la investigación promover la iniciación científica de los estudiantes? Para ello, consideramos tres objetivos específicos: caracterizar la propuesta de la enseñanza de las ciencias basada en la investigación; discutir la formación de profesores para la enseñanza de las ciencias por medio de la investigación como estrategia de iniciación científica; presentar contribuciones de una propuesta para el desarrollo de secuencias investigativas. Se adoptaron las directrices metodológicas de la investigación cualitativa y se realizaron entrevistas semiestructuradas para la recopilación de datos con la participación de dos profesores de un municipio situado en la región norte de la provincia de Paraná, Brasil. Para el análisis de los datos se utilizaron los procedimientos indicados por el Análisis de Contenido y la descripción de los saberes o conocimientos de Shulman como categorías a priori. Entre los principales resultados y debates se destacan las pruebas de las declaraciones de los profesores participantes, los cuales muestran que el saber predominante en sus declaraciones se refiere al saber pedagógico, seguido del conocimiento pedagógico del contenido y el conocimiento del contenido. Evidencias de manifestaciones de cambio de pensamiento o actitud hacia sus prácticas pedagógicas también surgen de sus relatos. Otro resultado observado se refiere a la aplicación de la propuesta a los estudiantes, lo que destacó la promoción de los momentos de iniciación científica.

\section{Palabras clave}

enseñanza de las ciencias en la investigación; saberes o conocimientos docentes; formación de profesores; iniciación científica 


\section{Introdução}

Nas últimas décadas tem-se observado esforços de pesquisadores e educadores em promover a educação dos estudantes de forma a desenvolverem conhecimento e apreensão de ideias científicas, bem como uma compreensão de como os cientistas estudam o mundo natural. Este pensamento tem sido as bases para as reformas educacionais, principalmente nos Estados Unidos da América (National Research Council [NRC], 1996; 2000; 2012; 2015; Next Generation Science Standards [NGSS], 2013). No Brasil, este movimento se revela de forma mais explícita nas orientações curriculares com a recente publicação da Base Nacional Comum Curricular (BNCC) (Ministério da Educação [MEC], 2017). Na BNCC, o processo investigativo científico precisa ser entendido como elemento central na formação dos estudantes e, além disso, proporcionar aos estudantes a aproximação aos processos, às práticas e aos procedimentos da investigação científica de forma gradativa (Sasseron, 2018).

Dentro desses aspectos, os estabelecimentos educacionais da Educação Básica têm o dever de oportunizar aos estudantes o desenvolvimento de seus pensamentos e ideias, conciliando-os, cada vez mais, com os modos científicos acessados por meio de informações, de observações e de investigações (Sasseron e Duschl, 2016). Pelo exposto, a escola possui a prerrogativa social e educacional de ensinar o conhecimento científico desde os primeiros anos da escolarização.

Nesse contexto, a prática pedagógica assume sua relevância como foco da formação docente inicial e continuada, tendo em vista a apropriação de estratégias de ensino e o aprimoramento profissional com ênfase para a docência. Em especial, destacamos o ensino de Ciências que tem despertado estudos quanto aos modos de ensinar que privilegiam a pesquisa, a experimentação, a observação, o registro sistematizado e a aprendizagem da linguagem científica. Da mesma forma, o papel do professor neste processo é considerado fundamental (Dobber et al., 2017). Alguns autores têm enfatizado a necessidade do desenvolvimento profissional dos professores a fim de aprimorar os saberes ou conhecimentos necessários ao enfrentamento dos desafios na implementação das atividades (em sala de aula) fundamentadas no agir e no pensar do cientista, bem como os saberes ou conhecimentos docentes para a superação desses desafios (Yang, Liu e Gardella Jr., 2018; Alake-Tuenter et al., 2012; Alake-Tuenter et al., 2013; Sorge et al., 2019). Entre os saberes ou conhecimentos destacam-se, principalmente, os saberes ou conhecimentos docentes de Shulman $(1986,1987)$.
Nessa perspectiva, sublinhamos, dentre as tendências para o ensino de Ciências, a prática docente por investigação como uma oportunidade estratégica, a ser desenvolvida pelo professor em suas aulas, para a iniciação científica ${ }^{1}$. Desse modo, admitimos que o ensino de Ciências nos anos iniciais do Ensino Fundamental assume uma particularidade por meio do ensino por investigação, tendo em vista as diversas situações de ensino e de aprendizagem para alunos e professores.

Diante desses posicionamentos e considerações, para o desenvolvimento da pesquisa, cujos resultados apresentamos neste artigo, assumiu-se o ensino de Ciências por investigação como estratégia de iniciação científica para estudantes dos anos iniciais do Ensino Fundamental e como conteúdo formativo para professores da Educação Básica. Fatos que nos conduziram a buscar por evidências dos saberes ou conhecimentos docentes, assim como de mudanças de pensamentos e posturas, a partir dos relatos de dois professores (sujeitos desta pesquisa), participantes de um projeto denominado Proposta para o desenvolvimento de sequências investigativas que visava desenvolver atividades com estudantes, em sala de aula, fundamentadas no ensino de Ciências por investigação.

A questão principal que norteou este desenvolvimento foi: de que maneira uma proposta de formação de professores para o ensino de Ciências por investigação pode promover a iniciação científica dos estudantes? Todavia, outras questões secundárias precisaram ser formuladas para que atingíssemos nossos objetivos. Entre elas destacamos duas: 1) Quais indícios dos saberes ou conhecimentos docentes de Shulman são manifestados pelos professores a partir dos seus depoimentos, quando da apresentação de suas percepções e reflexões relacionadas às atividades desenvolvidas com base no ensino de Ciências por investigação? 2) Quais manifestações de mudança de pensamento ou posturas dos professores, a respeito de suas ações em sala de aula, podem ser evidenciadas a partir de suas falas com relação às atividades desenvolvidas e que foram fundamentadas no ensino de Ciências por investigação?

Para responder a essas questões, uma primária e duas secundárias, organizamos o artigo da seguinte forma: 1) apresentação de alguns pressupostos relativos ao ensino de Ciências por investigação, bem

10 termo iniciação científica refere-se, neste artigo, ao conjunto de atividades fundamentadas no ensino de Ciências por investigação desenvolvidas e aplicadas em sala de aula pelos professores participantes do projeto. Deste contexto foi elaborado um produto educacional denominado: Proposta para o desenvolvimento de sequências investigativas. 
como suas características e estratégias; 2) discussão de alguns pontos referentes à formação de professores para o ensino de Ciências por investigação e os saberes ou conhecimentos docentes de Shulman (1986, 1987); 3) descrição dos encaminhamentos metodológicos assumidos para o desenvolvimento desta pesquisa; 4) organização e interpretação das percepções e das reflexões dos professores sobre o desenvolvimento das atividades vinculadas à proposta; e 5) considerações conclusivas a que este movimento nos encaminhou.

\section{Ensino de ciências por investigação: alguns destaques}

Diferentes especificações sobre abordagens baseadas em investigação podem ser encontradas na literatura acadêmica internacional. 0 termo geral mais utilizado é a educação fundamentada em investigação (inquiry- $b a$ sed education). Várias maneiras de implementar ideias de educação baseada em investigação são distinguidas dentro de diferentes modelos na literatura, por exemplo: aprendizagem baseada em investigação científica; aprendizagem baseada em problemas; aprendizagem baseada em projetos (Dobber et al., 2017).

Segundo Zômpero e Laburú (2011), o ensino por investigação era difundido como inquiry e na literatura assume várias definições, entre elas: ensino por descoberta; aprendizagem por projetos, por questionamentos, por resolução de problemas, por sequências investigativas, entre outras.

Partindo desse conjunto de definições, cabe destacar que ensinar Ciências a partir da perspectiva da investigação consiste em valorizar os seus produtos e seus processos, viabilizando conhecimentos que integram uma maneira de construir entendimento sobre o mundo, os fenômenos naturais e os impactos destes em nossas vidas (Sasseron, 2015). Dessa forma, o processo parte dos conhecimentos prévios dos alunos, em seguida se investiga as ideias recorrentes e são elencadas novas formas de compreender os acontecimentos e os conhecimentos relacionados a eles.

Segundo Vieira, o ensino por investigação supera a visão fragmentada no ensino de Ciências e propõe diálogos, discussões e interpretações que avançam no ato de se apropriar do conhecimento científico produzido pela humanidade. 0 que nos leva a considerar que "ensinar por investigação significa fazer um movimento de aproximar os conhecimentos científicos dos conhecimentos escolares, mobilizando a atividade do aprendiz ao invés de sua passividade" (2012, p. 20).
Com base nesse contexto, são procuradas alternativas e estratégias de ensino que superem a fragmentação dos conteúdos e possibilite essa aproximação do aluno com a participação ativa no processo de aprendizagem e na sistematização do conhecimento.

Uma crítica comum aponta para a insuficiência do ensino centrado em "fatos científicos" e em definições de conceitos, leis e princípios. A alternativa a esse tipo de ensino seria a problematização dos fenômenos e uma negociação dos sentidos de um dado conjunto de conceitos, modelos e teorias que nos permitem interpretar esses fenômenos de modo coerente. (Sá et al., 2007, p. 3, grifo dos autores)

Partindo desse pressuposto, ao mesmo tempo em que se busca problematizar os conteúdos em seu uso cotidiano e a percepção de fenômenos que ocorrem pelo mundo, o ensino por investigação assume maior destaque quando relacionado com as vivências e as experiências dos alunos para ampliar horizontes que o conduzam à compreensão do contexto que o cerca.

Tais constatações conduzem-nos a refletir sobre as características do ensino por investigação, ou seja, assumi-lo como aquele que é:

capaz de buscar a informação pretendida através das discussões entre os alunos, com a ajuda do professor, deixando um pouco de lado o processo curricular exaustivo e estruturado. Trata-se de buscar respostas a partir de problemas reais e culturalmente relevantes, a partir de experimentos inspirados pelas próprias discussões em sala de aula. (Vieira, 2012, p. 21)

Ainda sobre essas características, Zômpero e Laburú (2011) esclarecem que as atividades investigativas precisam apresentar:

o engajamento dos alunos para realizar as atividades; a emissão de hipóteses, nas quais é possível a identificação dos conhecimentos prévios dos mesmos; a busca por informações, tanto por meio dos experimentos como na bibliografia que possa ser consultada pelos alunos para ajudá-los na resolução do problema proposto na atividade; a comunicação dos estudos feitos pelos alunos para os demais colegas de sala, refletindo, assim, um momento de grande importância na comunicação do conhecimento, tal como ocorre na Ciência, para que o aluno possa compreender, além do conteúdo, também a natureza do conhecimento científico que está sendo desenvolvido por meio desta metodologia de ensino. (Zômpero e Laburu, 2011, p. 79)

De acordo com Carvalho (2013), o ensino por investigação está subsidiado por etapas e raciocínios pedagógicos que visam desenvolver uma experimentação científica. Convém explicitar que nessa perspectiva a 
experimentação se diferencia de uma experimentação espontânea, tendo em vista, por exemplo, as atividades de elaboração e teste de hipóteses relacionadas aos conteúdos a serem investigados.

Nessa mesma direção argumentativa, Maués e Lima (2006) afirmam que os alunos que são expostos a processos investigativos que envolvem a identificação de suas curiosidades, a elaboração de questões, o levantamento de hipóteses, a análise de evidências e a comunicação dos resultados a outras pessoas, inclusive aos próprios colegas do sistema educacional, movem-se da passividade. Todavia, em um ambiente investigativo, estudantes e professores têm a oportunidade de elaborar o conhecimento científico, de modo que os professores não são os únicos detentores de conhecimento e os estudantes, também, tornam-se ativos neste processo de aprendizagem, ou seja, professores e estudantes aprendem.

Outra característica importante no ensino por investigação está, principalmente, no papel que o aluno e o professor assumem durante a pesquisa de um determinado tema. Sá et al. (2007) exemplificam que em atividades tradicionais no ensino de Ciências, a definição do problema, a sinalização do objetivo e a escolha da metodologia são todos definidos pelos professores, cabendo aos alunos apenas acolher os dados e chegar à resposta da atividade. Já no caso das atividades investigativas, essas tarefas passam a ser 'orientadas' pelo professor e 'assumidas' pelos alunos, ou seja, "nas atividades práticas voltadas para investigação, a identificação de problemas, a formulação de hipóteses, a escolha dos procedimentos, a coleta de dados e a obtenção de conclusões, são tarefas dos alunos" (p. 3).

Porém, cabe destacar que uma sequência de ensino investigativo parte de algumas atividades-chave. Assim, podemos iniciar com a delimitação de um problema, na qual os alunos possam trabalhar com variáveis relevantes do fenômeno científico central do conteúdo programático (Carvalho, 2013). Em seguida, faz-se necessário a sistematização do conhecimento adquirido pelos alunos.

Para Carvalho (2013), a próxima etapa seria propiciar a contextualização do conhecimento cotidiano dos alunos, o que permitiria a eles constatarem a importância da aplicação do conhecimento elaborado do ponto de vista social, levando-os ao aprofundamento do conhecimento. Por conseguinte, o autor sugere algumas etapas para melhor desempenho no planejamento e para o gerenciamento da classe, conforme observamos na Tabela 1.

Tabela 1. Etapas para o desenvolvimento de atividades investigativas

\begin{tabular}{|l|l|l|}
\multicolumn{2}{|c|}{ Orientações para o desenvolvimento de atividades investigativas } \\
\hline \multicolumn{1}{|c|}{ Etapas } & $\begin{array}{l}\text { O procedimentos } \\
\text { põe o tema, esclarecendo que a partir deste tema poderão surgir vários pro- } \\
\text { blemas, porém cada grupo se dedicará a um problema. Os alunos devem } \\
\text { elaborar um problema a ser investigado a partir do tema escolhido. }\end{array}$ \\
$\begin{array}{l}\text { 1. A problematização inicial } \\
\text { 2. A sistematização da reso- } \\
\begin{array}{l}\text { lução do problema: resolução } \\
\text { do problema pelos alunos. }\end{array}\end{array}$ & $\begin{array}{l}\text { Nesta etapa as ações manipulativas que dão condições aos alunos de levan- } \\
\text { tar hipóteses, isto é, ideias para resolvê-lo. O aluno anota a resposta ini- } \\
\text { cial para seu problema (possível solução). Então é chegada a hora de traçar } \\
\text { um caminho e desenvolver a pesquisa, em conjunto com os alunos traçar a } \\
\text { metodologia da pesquisa. Após coletar os dados é preciso analisá-los jun- } \\
\text { tamente com o aporte teórico e interpretar os resultados da pesquisa. }\end{array}$ \\
\hline $\begin{array}{l}\text { 3. A contextualização do con- } \\
\text { hecimento: sistematização dos } \\
\text { conhecimentos elaborados nos } \\
\text { grupos e dos conhecimentos. }\end{array}$ & $\begin{array}{l}\text { Os alunos mostrarão, por meio do relato do que fizeram, as hipóteses que } \\
\text { deram certo e como foram testadas. Nesse sentido, a conclusão da pes- } \\
\text { quisa consiste em comparar a hipótese inicial com os resultados. }\end{array}$ \\
\hline
\end{tabular}

Fonte: Adaptação feita a partir de Carvalho (2013) e Zômpero e Laburú (2011).

Ressaltamos que não se deve exigir nos anos iniciais do Ensino Fundamental, que os estudantes sigam o rigor do método científico, entretanto, é nessa etapa que se inicia as oportunidades, como destacam Campos e Nigro (1999): o desenvolvimento de algumas atividades que viabilizem os primeiros passos para a observação dos fatos; o levantamento de problemas, de hipóteses; a elaboração de palpites sobre seus próprios questionamentos. 
Nesse sentido, apontamos que, por meio do ensino por investigação, os professores e os alunos são convidados a participar ativamente do processo de ensino e de aprendizagem, o que nos permite elencar de forma sintética algumas características do ensino por investigação, as quais organizamos em duas colunas (descrição da característica, autor de origem) na Tabela 2 exposto na continuidade.

Tabela 2. Características do ensino por investigação

\begin{tabular}{|c|c|}
\hline Característica & Autor(es) \\
\hline $\begin{array}{l}\text { Privilegia a observação dos fatos, o levantamento de problemas, de hipóteses e a elaboração de } \\
\text { palpites de próprios questionamentos pelos alunos. }\end{array}$ & $\begin{array}{l}\text { Campos e } \\
\text { Nigro (1999) }\end{array}$ \\
\hline $\begin{array}{l}\text { Envolve a formação do professor-pesquisador para que este possa desenvolver pesquisa com } \\
\text { seus alunos e estes, por sua vez, se tornem alunos-pesquisadores. }\end{array}$ & $\begin{array}{l}\text { Cunha e Krasilchik } \\
\qquad(2000)\end{array}$ \\
\hline $\begin{array}{l}\text { Envolve processos investigativos, nos quais os alunos são participantes ativos elaborando ques- } \\
\text { tões, levantando hipóteses, analisando evidências e comunicando os seus resultados aos demais. }\end{array}$ & $\begin{array}{l}\text { Maués e Lima } \\
\quad(2006)\end{array}$ \\
\hline $\begin{array}{l}\text { As atividades são orientadas pelo professor e assumidas pelo aluno no processo de investigação. Ini- } \\
\text { cia-se com discussões que desencadeiam em um processo educativo parte da própria importância } \\
\text { dada pelo problema identificado, pela curiosidade e pelas inquietações apresentadas pelos alunos. }\end{array}$ & $\begin{array}{l}\text { Sá et al. } \\
\text { (2007) }\end{array}$ \\
\hline $\begin{array}{l}\text { Destaca o engajamento dos alunos para realizar as atividades; a emissão de hipóteses, nas quais } \\
\text { é possível a identificação dos conhecimentos prévios dos mesmos. Busca por informações, tanto } \\
\text { por meio dos experimentos como na bibliografia que possa ser consultada pelos alunos para } \\
\text { ajudá-los na resolução do problema proposto na atividade. A comunicação dos estudos feitos } \\
\text { pelos alunos para os demais colegas de sala, refletindo a natureza do conhecimento científico } \\
\text { que está sendo desenvolvido por meio desta metodologia de ensino. }\end{array}$ & $\begin{array}{l}\text { Zômpero e Laburú } \\
\text { (2011) }\end{array}$ \\
\hline $\begin{array}{l}\text { Busca por respostas a partir de problemas reais e culturalmente relevantes, a partir de experi- } \\
\text { mentos inspirados pelas próprias discussões em sala de aula. }\end{array}$ & $\begin{array}{l}\text { Vieira } \\
(2012)\end{array}$ \\
\hline $\begin{array}{l}\text { A busca pela solução de problemas leva os alunos à explicação do contexto, esclarecendo que Ciên- } \\
\text { cia é a explicação da natureza. Realiza-se por etapas: 1. A problematização inicial; } 2 \text {. A sistemati- } \\
\text { zação da resolução do problema: resolução do problema pelos alunos; } 3 \text {. A contextualização do } \\
\text { conhecimento: sistematização dos conhecimentos elaborados nos grupos e dos conhecimentos. }\end{array}$ & $\begin{array}{c}\text { Carvalho } \\
\text { (2013) }\end{array}$ \\
\hline
\end{tabular}

Fonte: Elaborado pelos autores com base nas referências estudadas.

Na próxima seção trazemos aspectos relevantes sobre as atividades investigativas, visando fundamentar o desenvolvimento de atividades diante da perspectiva de tomar o ensino por investigação como um conteúdo formativo para os professores que ensinam Ciências, bem como os saberes ou conhecimentos necessários para a implementação das atividades investigativas junto aos alunos da Educação Básica.

\section{Saberes ou conhecimentos docentes e o ensino investigativo: algumas implicações}

Quando se realiza uma leitura das publicações a respeito da formação de professores para a implementação do ensino por investigação em sala de aula, depara-se muitas vezes com questões do tipo: 0 que os professores precisam saber e ser capazes de fazer para usar o ensino por investigação de forma eficaz? Que tipos de desenvolvimento profissional podem ajudar os professores a desenvolver e usar estratégias baseadas em ensino e aprendizagem por investigação?

Diante desses questionamentos, pesquisadores, educadores e professores têm tentado compreender, esclarecer e delimitar os fundamentos e os processos para o desenvolvimento de atividades em sala de aula baseadas na investigação. A esse respeito podemos observar o que aponta o documento do NRC (2000) intitulado - Inquiry and the national science education standards: A guide for teaching and learning -, e que expõe a seguinte afirmação:

Para que os alunos compreendam o ensino por investigação (inquiry) e usem -no para aprender ciência, seus professores precisam estar bem versados em 
métodos de investigação e de pesquisa. No entanto, a maioria dos professores não teve oportunidade de aprender ciência através de investigação ou de conduzir pesquisas científicas. Nem muitos professores têm a compreensão e as habilidades que eles precisam para usar o inquiry de forma cuidadosa e apropriada em suas salas de aula. (p. 87, destaques e tradução nossa).

Dentro do contexto brasileiro, para dar início à discussão, cabe explicar dois conceitos importantes —-formação inicial e formação continuada- considerando a importância da formação docente para atuar na Educação Básica brasileira.

Cabe uma ressalva à Lei Federal n. 13.005 (2014), que aprova o Plano Nacional de Educação (PNE) 20142024, o qual traz como meta a disposição de que todos os docentes a serem admitidos na Educação Básica tenham formação em nível superior e que, consequentemente, a formação em nível médio (magistério) passaria a não ser mais um requisito mínimo para o exercício do magistério. Nesse sentido, a Lei n. 9.394 (1996), que institui as diretrizes e bases da educação nacional, define que:

Art. 62. A formação de docentes para atuar na educação básica far-se-á em nível superior, em curso de licenciatura, de graduação plena, em universidades e institutos superiores de educação, admitida, como formação mínima para o exercício do magistério na educação infantil e nos 5 (cinco) primeiros anos do ensino fundamental, a oferecida em nível médio na modalidade normal.

Portanto, a licenciatura plena em Pedagogia é a formação mínima para atuar nos anos iniciais do Ensino Fundamental. Dentre as incumbências que ela destaca está a de ministrar a disciplina de Ciências (Lei n. 9.394, 1996). De tal modo, as demandas formativas do Pedagogo incluem a formação para a docência nos anos iniciais do Ensino Fundamental, abarcando inclusive ministrar as aulas da disciplina de Ciências. Lembramos que a disciplina de Ciências é uma das disciplinas que compõem a BNCC, a qual, nesta segunda etapa da educação brasileira, do primeiro ao quinto ano, é ministrada por um profissional que possui uma habilitação generalista e ampla para atuar como docente.

Salientamos que a formação inicial de professores é uma das fases da aprendizagem docente.

É importante registrar que no processo formativo dos professores, a formação inicial é uma das fases do desenvolvimento profissional e que, por isso, possui algumas limitações cujos impactos têm imposto a necessidade da criação de oportunidades de formação continuada (Silva e Bastos, 2012, p. 153)
Assim, corroboramos com essa ideia de que a formação inicial pode e precisa ser complementada pela formação continuada, de maneira progressiva e contínua. "Professores deverão atualizar-se constantemente, de modo que não só se mantenham informados sobre o progresso da Ciência e Tecnologia como também que estejam prontos para discutir o seu significado" (Cunha e Krasilchik, 2000, p. 5). Paralelamente, a formação do profissional também se dá pela forma continuada que diz respeito a processos formativos realizados após a sua formação inicial, dando continuidade às suas aprendizagens do fazer docente (Resolução no 02, 2015).

Por conseguinte, a formação continuada tem que ser entendida como permanente, pois não se finda em uma ou outra oportunidade de capacitação profissional, mas sim nas diferentes e diversas possibilidades, seja vinculada diretamente à sua atuação in loco (formação continuada em serviço) ou relacionada a saberes da profissão de professor (formação continuada geral). A esse respeito, Garcia (1997, p. 54) pontua que:

\section{Um primeiro aspecto que nos parece conveniente destacar é a necessidade de conceber a formação de professores como um continuum. Apesar de ser composto por fases claramente diferenciadas do ponto de vista curricular, a formação de professores é um processo que tem de manter princípios éticos, didáticos e pedagógicos comuns, independente- mente do nível de formação em causa.}

Defrontamos com um perfil formativo que permite perceber o processo como contínuo e permanente de desenvolvimento profissional. Schön (1992) aponta três estratégias formativas para esse perfil de professor reflexivo, que precisam ser exploradas e aprimoradas em sua prática pedagógica: reflexão na ação, reflexão sobre a ação e reflexão sobre a reflexão na ação. Comumente, o autor sinaliza também uma formação crítico-reflexiva que se realizará em três processos: desenvolvimento pessoal, desenvolvimento profissional e desenvolvimento organizacional.

Destacamos, a partir da perspectiva apontada anteriormente, a relevância da competência e da habilidade docente em pensar sobre os próprios desafios de sua prática. Desse modo, o professor busca recursos, estratégias e metodologias para sanar seus problemas advindos do contexto de sala de aula, fazendo com que a escola e a sala de aula se tornem um espaço e um tempo de formação que expressa sua qualidade diante dos múltiplos aspectos envolvidos com o ato da docência.

Tardif (2002) contribui para essa análise ao afirmar que a formação profissional do professor se faz também na organização de sua atividade de docência, 
principalmente nas relações entre professor-aluno na construção de saberes sobre o ato de ensinar. Dessa maneira,

o saber é sempre o saber de alguém que trabalha alguma coisa no intuito de realizar um objetivo qualquer. Além disso, o saber não é uma coisa que flutua no espaço: o saber dos professores é o saber deles e está relacionado com a pessoa e identidade deles, com a experiência de vida e com a sua história profissional, com suas relações com os alunos em sala de aula e com os outros atores escolares na escola etc. (p. 11)

Dando continuidade a essa discussão pontuamos que, segundo Tardif (2002), a construção dos saberes docentes é decorrente do exercício da docência (experiência pessoal), em instituições formativas de professores, com colegas de trabalho e por meio de outras formas de adquirir esse conhecimento da prática pedagógica. Para esse mesmo autor os saberes são categorizados em: 1) saberes da formação profissional - referentes aos conteúdos das Ciências da educação e da ideologia pedagógica, apropriados durante a formação em instituições oficiais de formação docente; 2) saberes disciplinares - que dizem respeito aos conhecimentos adquiridos na formação inicial nas universidades; 3) saberes curriculares - que se referem aos programas, aos objetivos, aos métodos que podem advir de diferentes fontes de aprendizagem; 4) saberes experienciais - que são aqueles apropriados por meio das experiências individuais e coletivas sobre o saber-fazer e o de saber-se (Tardif, 2002).

De forma similar Shulman $(1986,1987)$, na década de 1980 propôs, originalmente, sete bases de conhecimento que um professor precisa para criar um ensino de qualidade: 1) conhecimento do conteúdo (Content Knowledge [CK]]; 2) conhecimento pedagógico do conteúdo (Pedagogical Content Knowledge [PCK]); 3) conhecimento pedagógico (Pedagogical Knowledge [PK]]); 4) conhecimento curricular; 5) conhecimento dos alunos e suas características; 6) conhecimento do contexto educacional; 7) conhecimento dos fins, propósitos e valores educacionais. Atualmente, as três primeiras dessas bases do conhecimento, $\mathrm{CK}, \mathrm{PCK}$ e PK, são amplamente consideradas como o núcleo do conhecimento profissional dos professores (Grossman, 1990; Kirschner et al., 2016; Kleickmann et al., 2013; Sorge et al., 2019; van Driel, Berry e Meirink, 2014). Para descrever estes três conhecimentos de forma sintética, apresenta-se na sequência a Tabela 3.

A descrição é realizada a partir dos autores citados anteriormente e da indicação e organização elaborada por Harris, Mishra e Koehler (2009).

Tabela 3. Descrição dos conhecimentos-bases de Shulman

Saberes ou

Conhecimentos de Shulman mento Pedagógico

CK -Conhecimento do Conteúdo
Descrição

O conhecimento pedagógico é um conhecimento sobre os processos e as práticas de ensino e de aprendizagem, abrangendo propósitos educacionais, metas, valores, estratégias e muito mais. Essa é uma forma geral de conhecimento que se aplica ao aprendizado dos alunos, gerenciamento de sala de aula, planejamento e implementação de instruções e avaliação dos alunos. Inclui conhecimento sobre técnicas ou métodos usados na sala de aula, a natureza das necessidades e das preferências dos alunos e das estratégias para avaliar a compreensão do aluno. Um professor com conhecimento pedagógico compreende como os alunos constroem conhecimentos e adquirem habilidades de maneiras diferenciadas, bem como desenvolvem hábitos mentais e disposições para a aprendizagem. Como tal, o conhecimento pedagógico requer uma compreensão das teorias cognitivas, sociais e de desenvolvimento da aprendizagem e como elas se aplicam aos alunos na sala de aula.

Conhecimento do conteúdo é o conhecimento sobre o assunto a ser aprendido ou ensinado, incluindo, por exemplo, ciências do ensino médio, história do ensino médio, história da arte na graduação ou astrofísica no nível de pós-graduação. 0 conhecimento e a natureza da investigação diferem muito entre as áreas de conteúdo, e é extremamente importante que os professores entendam os "hábitos mentais" disciplinares apropriados ao assunto que ensinam. Para Shulman (1986; 1987), esse saber envolve mais que o simples domínio de conteúdo. Envolve a natureza e os significados dos conhecimentos. 0 conhecimento do conteúdo inclui conhecimento de conceitos, teorias, ideias, estruturas organizacionais, métodos de evidência e prova, bem como práticas e abordagens estabelecidas para desenvolver esse conhecimento em uma disciplina específica. 


\begin{tabular}{|c|c|}
\hline $\begin{array}{c}\text { Saberes ou } \\
\text { Conhecimentos } \\
\text { de Shulman }\end{array}$ & Descrição \\
\hline $\begin{array}{l}\text { PCK - Conheci- } \\
\text { mento Pedagó- } \\
\text { gico do Conteúdo }\end{array}$ & $\begin{array}{l}\text { O conhecimento pedagógico do conteúdo é a interseção e interação da pedagogia e do conhe- } \\
\text { cimento de conteúdo. O PCK é o amálgama entre os outros dois conhecimentos descritos, é o } \\
\text { conhecimento aplicável a uma área de conteúdo específica. Ele abrange o conhecimento essen- } \\
\text { cial do ensino e aprendizagem de currículos baseados em conteúdo, bem como a avaliação e o } \\
\text { relatório dessa aprendizagem. Uma conscientização sobre o conhecimento prévio dos alunos, } \\
\text { estratégias alternativas de ensino em uma determinada disciplina, conceitos errôneos comuns } \\
\text { relacionados ao conteúdo, como criar links e conexões entre diferentes ideias baseadas em } \\
\text { conteúdo e a flexibilidade resultante da exploração de maneiras alternativas de olhar para a } \\
\text { mesma ideia ou problema, e mais, são expressões do conhecimento pedagógico do conteúdo e } \\
\text { são essenciais para o ensino efetivo. }\end{array}$ \\
\hline
\end{tabular}

Fonte: Elaborado pelos autores com base nas referências citadas.

Dentre os três saberes ou conhecimentos descritos na Tabela 3, PCK é considerado o principal saber ou conhecimento para a prática do professor em sala de aula.

A este propósito Gil-Pérez contribui com sua análise da formação docente de Ciências, sinalizando a necessidade de se pensar nos limites e nas possibilidades da formação inicial e da continuada diante da constituição da identidade profissional.

\begin{abstract}
Começa-se a questionar as visões simplistas sobre a formação dos professores de Ciências e a compreender a necessidade de uma preparação rigorosa para garantir uma docência de qualidade. Isso não é possível, obviamente, no tempo necessariamente limitado da formação inicial: as exigências de formação são tão grandes que procurar cumpri-las no período inicial conduziria ou a uma duração absurda ou a um tratamento superficial. Por outro lado, muitos dos problemas do processo ensino-aprendizagem não adquirem sentido até que o professor os tenha enfrentado em sua própria prática. Por tudo isso, a formação dos professores tende cada vez mais a apoiar-se em uma formação inicial relativamente breve (a duração habitual de uma licenciatura) e em uma estrutura de formação permanente dos professores em serviço. (1996, p. 73)
\end{abstract}

Com base nesses apontamentos mencionados anteriormente, percebemos que é necessário pensar a formação continuada como parte integrante da qualificação dos professores, bem como articulada ao trabalho desenvolvido por eles. Consequentemente, é necessário viabilizar oportunidades e momentos formativos que permitam considerar os contextos social e cultural do professor, suas reais condições de trabalho, sua valorização profissional, além dos desafios presentes em seu contexto escolar e em sua sala de aula, no que tange ao ensino dos conhecimentos científicos.
É cada vez mais urgente pensar na formação docente para o ensino de Ciências pensado para/na formação de cidadãos críticos, "torna-se necessário o desenvolvimento profissional dos professores, a fim de que os conhecimentos científicos sejam discutidos e que o Ensino de Ciências se realize com qualidade" (Silva e Bastos, 2012, p. 151). Nesse contexto, Silva e Bastos afirmam:

Em síntese, (re)pensar/discutir a formação docente para o Ensino de Ciências significa perceber que a valorização do conhecimento científico e tecnológico pela sociedade contemporânea exige do professor a realização de um trabalho que rompa com os conceitos que lidam com as Ciências de forma dogmática, acrítica e descontextualizada da realidade global, a fim de que ele possa contribuir para a formação de cidadãos críticos, alfabetizados cientificamente. (2012, p. 152)

Em suma, interpretamos que a formação continuada dos docentes é uma ação pedagógica que precisa ser investida, investigada e analisada a partir do olhar dos professores e dos desafios, bem como promover oportunidade formativa que vai ao encontro de suas necessidades pedagógicas disciplinares.

Nessa perspectiva, defendemos que o ensino por investigação assume também o caráter de um conteúdo formativo para os professores com relação ao ensino de Ciências e pode fazer parte dos programas de formação continuada dos docentes da Educação Básica.

De acordo com Carvalho (2013), o ensino por investigação consiste em um conjunto de orientações pedagógicas para desenvolver uma sequência de atividades abordando um tópico do programa escolar em que cada aula é planejada. Portanto, esse conjunto de encaminhamentos pedagógicos indica ao 
professor possibilidades para o ensino dos conteúdos em sala de aula, e assim, corrobora para seu aperfeiçoamento profissional, quando essas orientações são apropriadas em momentos formativos quando já está atuando profissionalmente.

Somado a isso, ensinar aos professores a desenvolver atividades investigativas em Ciências amplia as possibilidades para que ele promova a iniciação científica dos estudantes por meio de um processo sistematizado para a alfabetização científica por meio da pesquisa. Sá et al. (2007) esclarece que:

\begin{abstract}
as atividades investigativas têm seu potencial pedagógico aumentado na medida em que contribuem para um ensino mais interativo, dialógico e capaz de persuadir os alunos a compreender a validade das explicações científicas dentro de certos contextos. Desse modo, superar-se-ia um ensino de ciências centrado em discursos autoritários, prescritivos e dogmáticos. (p. 5)
\end{abstract}

Concordando com Sasseron (2015), o ensino por investigação ultrapassa o âmbito de uma metodologia de ensino apropriada apenas a certos conteúdos e temas, tendo em vista que ele pode ser utilizado em diferentes aulas para vários conteúdos. Assim, o autor expressa a intenção de que é necessário que o professor faça com que os alunos se engajem nas discussões ao passo em que tenham contato com fenômenos naturais, na busca de resolução de um problema, testem em situações práticas, desenvolvam raciocínios investigativos, análises descritivas e interpretativas e avaliação do processo de pesquisa que são utilizadas na prática científica.

Uma fala recorrente entre educadores e pesquisadores da educação em ciências é que a aprendizagem dos estudantes é mais efetiva quando eles são convidados a trazer sua experiência pessoal para o contexto escolar e quando eles têm oportunidades de realizar investigações, tomar consciência de suas ideias prévias, e estruturar novas maneiras de compreender os temas e os fenômenos em estudo. (Sá et al., 2007, p. 3)

Acreditamos que a solução de problemas leve os alunos à explicação do contexto, esclarecendo que Ciência é a explicação da natureza, e não se deseja a formação de um cientista, mas sim a criação de um ambiente investigativo (Carvalho, 2013). Nesse cenário, os alunos são ensinados no processo simplificado do trabalho científico e, assim, ampliam sua cultura científica ampliando a linguagem científica.

Uma vez que o ensino por investigação almeja “[...] levar os alunos a pensar, debater, justificar suas ideias e aplicar seus conhecimentos em situações novas, usando os conhecimentos teóricos" (Azevedo, 2013, p. 20), o professor pode promover durante a prática investigativa o contato dos alunos com atividades diversificadas. Essas atividades visam despertar a reflexão sobre um problema ou uma investigação, bem como propiciar a elaboração e a sistematização de conhecimentos.

As atividades investigativas constituem um recurso pedagógico, dentre outros, que o(a) professor(a) pode utilizar para diversificar sua prática no cotidiano escolar. São atividades basicamente centradas na mobilização dos alunos em busca de respostas e são potencializadoras do desenvolvimento da autonomia, capacidade de tomada de decisões, de avaliação e de resolução de situações-problema. (Sá et al., 2007, p. 11)

Acreditamos que o ensino por investigação nos anos iniciais do Ensino Fundamental propicia o primeiro contato com a iniciação científica. Tal pressuposto parte da ideia de Arce, Silva e Varotto (2011), quando diz que a exposição dos alunos aos fenômenos científicos, não só leva a uma compreensão melhor de conceitos científicos, como também do uso da linguagem científica que influencia o desenvolvimento destes conceitos. Nesse caso, ressaltamos que a disciplina de Ciências apresenta meios para desenvolverem tal pensamento.

Dessa maneira, percebemos que a partir da iniciação científica o interesse do aluno é despertado à medida que ele se apropria dos conhecimentos construídos historicamente e os aprofunda por meio da pesquisa. Consequentemente, esse processo investigativo leva o aluno a produzir conhecimentos científicos, uma vez que devidamente orientados sistematiza conceitos e estabelece novas conexões diante da ciência. Além disso, o ato da pesquisa, logo nos primeiros anos de escolarização, estimula a criatividade por meio do confronto com problemas instigantes da realidade com as produções científicas que os estudantes começam a ter contato.

Portanto, é imprescindível que o professor compreenda as diversas demandas contemporâneas, perceba o seu papel como agente de transformação e, consequentemente, estimule os educandos, considerando as suas especificidades, a perceberem, a discutirem e a buscarem soluções para a realidade social na qual estão inseridos (Silva e Bastos, 2012, p. 152)

Nessa perspectiva, o professor, por meio da experiência formativa sobre o ensino por investigação, adquire ferramentas teóricas e práticas para ampliar e privilegiar a iniciação científica no ensino de Ciências. Assim, em suas aulas de Ciências, o docente estimulará os estudantes a buscarem soluções para 
os problemas evidenciados de sua realidade e vivenciando a elaboração do conhecimento científico conforme forem encontrando as respostas. Essas possibilidades formativas tornam-se ambientes importantes no desenvolvimento de saberes e habilidades necessárias ao professor. Nesse sentido, este artigo tem por objetivo identificar indícios dos saberes ou conhecimentos docentes de Shulman, bem como de mudanças de pensamentos e posturas, a partir das falas pertinentes às entrevistas de dois professores participantes do projeto - Proposta para o desenvolvimento de sequências investigativas - que objetivava desenvolver atividades em sala de aula baseadas no ensino de Ciências por investigação com estudantes dos anos iniciais do Ensino Fundamental. Na continuidade, apresentamos alguns detalhes dos aspectos metodológicos em que essa pesquisa se pautou.

\section{Aspectos metodológicos}

Optou-se pela pesquisa qualitativa, pois seus pressupostos indicam possibilidades estratégicas de estudo no processo de ensino e de aprendizagem, viabilizando a extração de riqueza de detalhes dos dados coletados (Bogdan e Biklen, 1994).

Cabe destacar que os dados foram resultados da aplicação de um produto educacional para o ensino de Ciências junto a dois professores de um sistema municipal de ensino, em uma escola localizada no norte do estado do Paraná. Tal proposta tinha em vista a realização de uma atividade de formação continuada, tendo como objetivo que os professores se apropriassem da perspectiva do ensino de Ciências por investigação e desenvolvessem com seus alunos do quinto ano do Ensino Fundamental sequências investigativas ${ }^{2}$ a partir das orientações pedagógicas recebidas.

Como instrumento de coleta de dados escolheu-se a entrevista, realizada a partir de um roteiro semiestruturado, conforme indicações de Lüdke e André (2013). As questões elaboradas para essas interpelações objetivaram levantar as percepções e as reflexões dos professores acerca: da participação no Projeto; do ensino de Ciências; da utilização do produto educacional; de sua formação docente e do envolvimento dos alunos durante a sequência de atividades investigativas desenvolvidas.

2 Tais sequências foram desenvolvidas e aplicadas junto aos estudantes, os quais testaram hipóteses e concluíram diversos trabalhos de investigação, que foram impressos em banners que culminaram na apresentação da I Mostra de Iniciação Científica, promovida pela secretaria municipal de ensino.
Primeiramente, para sistematizar os dados obtidos por meio da entrevista com os docentes, transcrevemos as falas em arquivos de texto nomeados pelas siglas adotadas para cada um dos participantes (professor P1 e professor P2). Enfatizamos que as falas foram redigidas mantendo sua originalidade argumentativa e sofrendo apenas pequenas adequações pautadas nas normas cultas da Língua Portuguesa.

Dentre as várias abordagens da pesquisa qualitativa, optou-se pela Análise de Conteúdo (AC), sendo considerada por nós aquela que melhor possibilita elaborar respostas às nossas questões de pesquisa, pois orienta na direção de um entendimento interpretativo do fenômeno observado.

Entre os procedimentos da AC, a fragmentação dos dados coletados, sua codificação e reorganização, permite atingir uma representação do conteúdo ou de sua expressão sobre o fenômeno, capaz de esclarecer ao pesquisador as características e as essências do texto (Bardin, 2011).

Com base nisso, foram realizadas leituras do material transcrito com as falas dos docentes participantes da pesquisa, um estado organizado e já interpretado desses relatos foi elaborado no Tabela 3 (apresentada anteriormente). Nele acomodamos as manifestações, segundo a relação com a descrição dos saberes ou conhecimentos de Shulman.

Para auxiliar nesse processo, foi importante criar uma codificação para essas unidades (fragmentações), indicando os fragmentos interpretados por E (referente ao Excerto) seguido por um número, estabelecido em ordem numérica contínua e crescente, ou seja, E-1, E-2, E-3 [...], que consideraram os depoimentos dos dois professores.

Nessas falas procurávamos indícios de algum dos saberes ou conhecimentos indicados no Quadro 3 e que foram assumidos como categorias a priori e, também, manifestações de mudança de pensamento ou postura em relação à prática em sala de aula. 0 resultado desse movimento interpretativo encontra-se nas Tabelas 4 (relatos de P1) e 5 (relatos de P2), inseridos na continuidade ${ }^{3}$.

3 Devido à extensão das entrevistas, para este artigo, selecionamos somente as respostas que tinham relação com os saberes e conhecimentos indicados por Shulman ou com as mudanças de pensamento ou postura. Todavia, a completude dessas informações pode ser acessada em Araújo (2017). 


\section{Dados: apresentação, discussão e análise}

As discussões e análises foram realizadas separadamente. Em primeiro lugar trazemos as considerações de P1 e, posteriormente, as de P2. Também elaboramos dois gráficos (um para cada professor) com a quantidade de excertos pertinente a cada categoria. Para este artigo são apresentadas somente alguns excertos referentes aos relatos de P1 e P2, mas as interpretações consideram todos os excertos de forma que aqueles presentes nas Tabelas 4 e 5 ilustrem um movimento mais amplo de análise.

\section{Professor P1}

Na primeira coluna do quadro nominamos cada um dos saberes ou conhecimentos de Shulman, na segunda coluna organizamos os depoimentos selecionados e interpretados. Como eles foram fragmentados na ordem cronológica em que a entrevista ocorreu, sua numeração não segue a ordem crescente.

Tabela 4. Relatos do professor P1 categorizados

\begin{tabular}{|c|c|}
\hline $\begin{array}{l}\text { Saberes ou } \\
\text { Conhecimentos } \\
\text { de Shulman }\end{array}$ & Unidades \\
\hline $\begin{array}{l}\text { Conhecimento } \\
\text { Pedagógico - PK }\end{array}$ & $\begin{array}{l}\text { E-4 - Apesar de eles já terem terminado as provas, a gente consegue perceber que foi enten- } \\
\text { dido aquele assunto, aqueles conceitos, que conseguem aplicar hoje no dia a dia deles, então é } \\
\text { bem interessante, eu achei bem legal, eu achei ótimo. Mas assusta a gente olha aquele monte de } \\
\text { página e fala meu Deus não vou dar conta disso em um trimestre, quando eu peguei do primeiro } \\
\text { trimestre falei pra "CM". Isso aqui é para o ano todo né? Porque não vou dar conta disso. A gente } \\
\text { fica desesperada, porque na verdade é o desconhecido. A gente não sabe a metodologia, como } \\
\text { trabalhar, como fazer, mas depois que você começa a caminhar, aí vê que eles conseguem pegar. } \\
\text { E-12 - Eu achei que na minha turma melhorou muito no aspecto da criticidade deles. Eu achei } \\
\text { que eles ficaram mais críticos. Apesar de que a gente tem menos aulas de Ciências na verdade. } \\
\text { Mas assim, eu percebi que eles ficaram mais críticos, mais interessados nos assuntos. } \\
\text { E-24 - Porque a gente acaba direcionando mais tempo para a pesquisa. Principalmente quando } \\
\text { estava no final. Então, assim, eu fui dando conteúdo, fui aprimorando o projeto. Mas foi bem aper- } \\
\text { tado ali. Aí a gente acaba tendo que ter um jogo de cintura. Meu tema era do primeiro trimes- } \\
\text { tre e o desenvolvimento do projeto foi no segundo trimestre. Era outro conteúdo. Então eu fui } \\
\text { separando um tempo para isso. Como eu tenho três aulas de Ciências eu separei uma aula para } \\
\text { eles e duas para o conteúdo. Então assim, nessa aula eles tinham que fazer o trabalho, o projeto. } \\
\text { Eles já sabiam. Em uma aula a gente tem tantos minutos para fazer isso. Então eles mesmos já } \\
\text { foram se organizando em relação a isso. Porque eles já sabiam que eu tinha que dar os outros } \\
\text { conteúdos nas outras aulas. Então eu fui dividindo dessa forma. }\end{array}$ \\
\hline $\begin{array}{l}\text { Conhecimento do } \\
\text { Conteúdo - CK }\end{array}$ & $\begin{array}{l}\text { E-1 - Eu acredito que Ciências engloba tudo no cotidiano da criança, no cotidiano da nossa } \\
\text { vida. É tudo que a gente estuda relacionados aos meios vivos né e não vivos também. Então e as } \\
\text { Ciências nos ajuda muito. Nos ajuda a entender fenômenos que acontecem no nosso dia a dia, } \\
\text { na natureza, na vida das crianças e em tudo isso. } \\
\text { E- } 21 \text { - Então a gente fez a escolha do tema. Eu trabalhei as fases da lua. Que na verdade já era } \\
\text { um conteúdo deles do primeiro trimestre. Então eles já estavam sabendo o que que era. Na ver- } \\
\text { dade, o tema eu escolhi com eles, mas aí eu acabei induzindo, também, para que fossem as fases } \\
\text { da lua dentro do conteúdo. }\end{array}$ \\
\hline $\begin{array}{l}\text { Conhecimento } \\
\text { Pedagógico do } \\
\text { Conteúdo - PCK }\end{array}$ & $\begin{array}{l}\text { E-2 - Mas aí olhando o conteúdo e a "Coordenadora" auxiliou bastante a gente. Eu consegui } \\
\text { perceber que um interliga o outro. Então assim você consegue puxar o gancho de um conteúdo } \\
\text { pelo outro. Então assim como a gente vem de escola privada que é bem diferente. Digamos assim, } \\
\text { não tem essa interligação, são conteúdos fechados. Você ensina isso e pronto. Você ensina aquilo } \\
\text { e pronto. Não tem essa sistematização que nós temos aqui. Então assim, é um desafio todos os } \\
\text { dias para mim. Que é bem difícil mesmo eu consegui fazer tudo isso. } \\
\text { E-3 - E consigo fazer essa sistematização, essa ligação entre os conteúdos. Você consegue ir } \\
\text { voltando e recapitulando. } \\
\text { E-10 - Eles chegam com conhecimentos prévios. Mas eu percebo que são coisas totalmente } \\
\text { fora do científico. Então até eles conseguirem entender que cientificamente é isso comprovado } \\
\text { demora um pouquinho. }\end{array}$ \\
\hline
\end{tabular}




\begin{tabular}{|c|c|}
\hline $\begin{array}{c}\text { Saberes ou } \\
\text { Conhecimentos } \\
\text { de Shulman }\end{array}$ & Unidades \\
\hline $\begin{array}{l}\text { Manifestações } \\
\text { de Mudança de } \\
\text { Pensamento ou } \\
\text { Postura — MP }\end{array}$ & $\begin{array}{l}\text { E-8 - Agora a gente consegue buscar mais fontes, mais coisas. Trazer métodos diferenciados } \\
\text { para eles. Que antes era mais tipo assim: vou dar só isso e pronto. Acabou não tem mais, agora é } \\
\text { só isso aí. Agora não, a gente consegue buscar mais coisas. Interligar várias coisas uma na outra. } \\
\text { Na verdade, eu avalio que assim. Eu ainda tenho que aprender muito (risos), muito mesmo. Mas } \\
\text { avalio que agora esteja bom. Razoável. Estou buscando cada vez mais para ficar excelente. } \\
\text { E-19 - Mas eu acho assim. Eu como professora sempre não fui insegura. Mas eu sempre fui } \\
\text { daquela professora que eu colocava o conteúdo, e explicava e eu fazia. Entendeu? Não por eles. } \\
\text { Mas eu indicava para eles. E esse projeto é totalmente diferente do que eu estava acostumada } \\
\text { a fazer. Porque aí eu tive que deixá-los fazerem. Para eles terem autonomia. É difícil! É difícil a } \\
\text { gente deixá-los fazerem. Muitas vezes eu queria eu ir lá e ajudar. Eu ir lá e fazer. Mas ia perder } \\
\text { o objetivo do trabalho. Então assim. Me acrescentou muito como profissional. Porque aí eu os } \\
\text { deixei caminharem com as próprias pernas. }\end{array}$ \\
\hline
\end{tabular}

Fonte: Os autores

Na Figura 1 observamos de forma ágil essa quantidade de fragmentos acomodados na Tabela 4, o que nos dá uma ideia das percepções de $\mathrm{P} 1$ a respeito do fenômeno investigado.

Número de excertos de P1

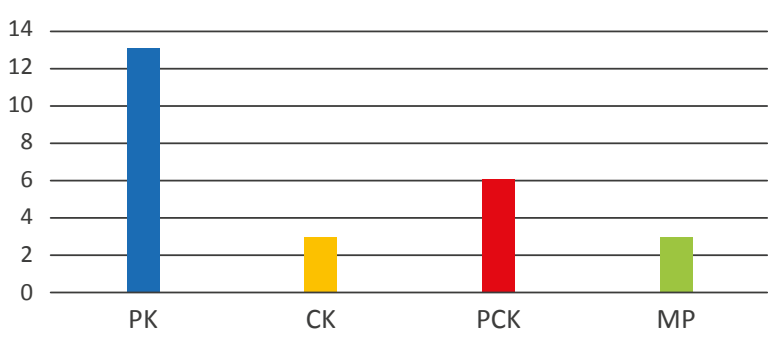

Figura 1. Número de excertos por categoria, segundo P1.

Fonte: Os autores

Observando a figura podemos perceber que mais da metade dos excertos das falas de P1 sobre o desenvolvimento das atividades, apontam indícios que correspondem ao conhecimento pedagógico (PK).

A partir dos relatos do professor, pode-se observar que o conhecimento pedagógico para ele caracteriza-se, principalmente, pela prática de ensino e aprendizagem relacionada ao gerenciamento da sala de aula, planejamento e implementação de instruções aos estudantes, como registrado nos excertos E-4 e E-24. Da mesma forma que os conhecimentos sobre técnicas ou métodos utilizados em sala de aula e uma compreensão de como os estudantes constroem conhecimentos e adquirem habilidades (E-4 e E-12).
Pode-se, ainda, perceber que para P1 o saber pedagógico PK é dominante nas suas ações relacionadas ao ensino e à aprendizagem durante o desenvolvimento das atividades. Suas preocupações estavam relacionadas a aspectos de gerenciamento, planejamento, tempo para execução das atividades, métodos e técnicas na implementação da proposta fundamentada no ensino de Ciências por investigação.

Outro saber de Shulman que emerge das falas de P1 é o conhecimento pedagógico do conteúdo ( $\mathrm{PCK}$ ), considerado por muitos pesquisadores o coração da prática do professor em sala de aula. É o conhecimento considerado fundamental para implementação de propostas curriculares, bem como dos currículos fundamentados no ensino por investigação. É a interseção e interação do saber ou conhecimento pedagógico com o conhecimento do conteúdo. 0 amálgama entre o conhecimento pedagógico e o conhecimento do conteúdo, como aponta Shulman. Evidências do PCK a partir dos relatos de P1 estão relacionadas, principalmente, à capacidade de sistematizar, de criar ligações e conexões entre diferentes ideias baseadas no conteúdo, de explorar maneiras alternativas de olhar para a mesma ideia e a conscientização sobre o conhecimento prévio dos estudantes. Esses pontos são manifestados nos excertos E-2, E-3 e E-10.

Com menor incidência nas falas analisadas, o conhecimento do conteúdo (CK) revela-se nos excertos E-1 e E-21. Para P1 esse conhecimento foi manifestado, principalmente, nas concepções da natureza do conhecimento, pois para Shulman esses saberes ou conhecimentos envolvem mais do que o simples domínio do conteúdo. Envolve a natureza e os significados dos conhecimentos. Também se observa 
indícios de conhecimento dos conceitos e ideias, bem como práticas e abordagens estabelecidas para desenvolver esse conhecimento em uma disciplina específica (E-21).

Outro ponto interessante que emerge das falas de P1, e que foram relacionados com as manifestações de mudança de pensamentos e posturas em relação à sua prática pedagógica, tangencia sua visão do desenvolvimento das atividades, saindo de uma condição estática, limitada, para uma busca de conhecimento, de novos instrumentos e de abordagens a serem usadas em sala de aula (E-8). Temos também o destaque à sua postura na condução das atividades em sala de aula, em que busca superar suas barreiras com relação a proporcionar maior autonomia aos estudantes (E-19).
De uma maneira geral, as falas de P1 remetem-nos ao conhecimento pedagógico (CK), explicitado predominantemente em suas percepções e reflexões a respeito das atividades desenvolvidas com base no ensino de Ciências por investigação. Em seguida o conhecimento pedagógico do conteúdo (PCK), evidenciado em 6 excertos. Por fim, temos 3 excertos que manifestarão sua relação com o conteúdo e outros 3 que trazem seus indicativos de mudanças de pensamentos e posturas sobre a prática pedagógica.

\section{Professor 2}

Da mesma forma com que apresentamos e organizamos as informações relacionadas aos relatos de P1, trazemos, na Tabela 5, as manifestações de P2 que foram elencadas para a discussão deste artigo.

Tabela 5. Relatos do professor P2 categorizados

\begin{tabular}{|c|c|}
\hline $\begin{array}{c}\text { Saberes ou } \\
\text { Conhecimentos } \\
\text { de Shulman }\end{array}$ & Unidades \\
\hline $\begin{array}{l}\text { Conhecimento } \\
\text { Pedagógico - PK }\end{array}$ & $\begin{array}{l}\text { E-29 - É que antes era assim, a gente trazia mais texto e era mais uma interpretação. Eu diria, } \\
\text { não entender o conhecimento, mas entender o processo. Hoje a gente tenta trazer mais opções } \\
\text { para eles saberem e poderem entender um pouco mais. Aí a gente os faz pensarem. Por que que } \\
\text { é isso? Por que, não é assim? Então não é só textos e perguntas. A gente acaba usando outros } \\
\text { instrumentos, para eles adquirirem o conhecimento. Dentro do possível, consigo sim conciliar } \\
\text { o conteúdo com o cotidiano do aluno. } \\
\text { E-42 - Ah eu acho que o inicial ali, (a questão do) problema. Você ter a noção do que é um pro- } \\
\text { blema. Porque daí é o inicial. o ponto de partida do trabalho. Porque se você não tiver noção } \\
\text { sobre o que vem. O que eles precisam estudar. Como? O trabalho fica fragmentado. Olha, em } \\
\text { minha opinião, ele estava bem completo, porque ele tinha os exemplos. Porque querendo ou } \\
\text { não, às vezes quando você está trabalhando com algo novo, você precisa de um exemplo. Então } \\
\text { ali sempre estava assim: comece assim, pode ser assim. Então eu achei bem completo nessa } \\
\text { questão. Não deixou nenhuma dúvida assim para mim. } \\
\text { E-43 - Então a gente tinha um dia específico que era a sexta. Pelo fato que a gente não tem } \\
\text { hora-atividade. E aí a gente foi seguindo as etapas mesmo. Eu fui seguindo a Proposta. Eu achei } \\
\text { que seria mais fácil. Tanto para mim, quanto para eles. Eu fui explicando cada parte. "Nessa parte } \\
\text { a gente precisa ver isso." Aí algumas coisas a gente fez em sala. Na verdade, a maioria a gente } \\
\text { construiu em sala. Porque eles começaram a discutir que: "ah! A gente não tem como ir na casa } \\
\text { do amigo". Então eles traziam o material de pesquisa. Daí a gente lia e discutia em sala. Diversas } \\
\text { vezes até a gente discutiu o assunto só de um grupo com a turma inteira. Porque assim era mais } \\
\text { socializado. Senão eles ficavam muito dispersos. }\end{array}$ \\
\hline $\begin{array}{l}\text { Conhecimento do } \\
\text { Conteúdo - CK }\end{array}$ & $\begin{array}{l}\text { E-26 - Ah! Ciência é um conhecimento do mundo, nosso conhecimento científico. } \\
\text { E-27 - Então a Ciência para mim vem em caminho a isso. Dá significado às coisas. O porquê que } \\
\text { a gente tosse. Porque a gente espirra. As descobertas. } \\
\text { E-28 - Porque Ciências em minha opinião. Assim, tem muita coisa que eu não lembro. Que a } \\
\text { gente não tem conhecimento científico, daí você vai pesquisar. Aí você vê que precisa retomar. } \\
\text { E-36 - Ah o ponto positivo é que você tem uma visão mais ampla (do conteúdo). }\end{array}$ \\
\hline $\begin{array}{l}\text { Conhecimento } \\
\text { Pedagógico do } \\
\text { Conteúdo - PCK }\end{array}$ & $\begin{array}{l}\text { E-30 - Os meios bióticos e abióticos eu estou trabalhando já com a questão. Que a gente está } \\
\text { fazendo um trabalho com Seara. Para eles irem pensando sobre isso também. Então a gente } \\
\text { tenta conciliar. } \\
\text { E-33 - [...] eles trazem bastante (conhecimento prévio). Eles querem sempre falar. "Porque meu } \\
\text { vizinho disse isso", e tal. }\end{array}$ \\
\hline
\end{tabular}




\begin{tabular}{|c|c|}
$\begin{array}{c}\text { Saberes ou } \\
\begin{array}{c}\text { Conhecimentos } \\
\text { de Shulman }\end{array}\end{array}$ & \multicolumn{1}{c|}{ Unidades } \\
\hline $\begin{array}{c}\text { Manifestações } \\
\text { de Mudança de } \\
\begin{array}{c}\text { Pensamento ou } \\
\text { Postura - MP }\end{array}\end{array}$ & $\begin{array}{l}\text { E-38 - Que querendo ou não foi um conhecimento para mim. Porque eu não tinha muita noção. } \\
\text { de você ensinar, ainda que eles errem os conceitos difíceis. } \\
\text { E-40 — Mas foi mais essa questão mesmo de positivo. Que fez com que olhasse para matéria de } \\
\text { Ciências de uma outra maneira. Os pontos negativos é que dá muito trabalho, não vou mentir. }\end{array}$ \\
\hline
\end{tabular}

Fonte: Os autores

Seguem, na Figura 2, as quantificações desses excertos da Tabela 5.

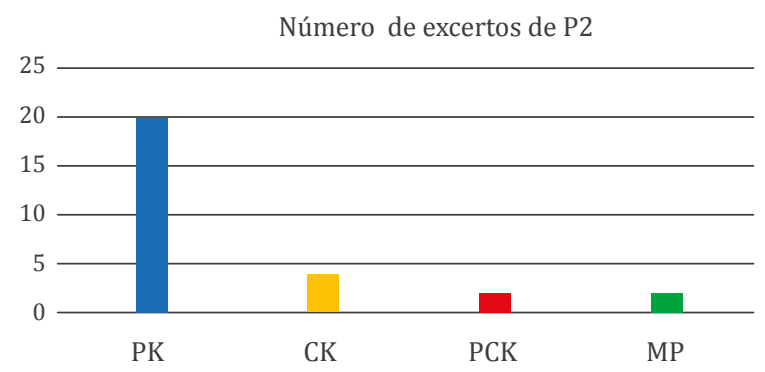

Figura 2. Número de excertos por categoria, segundo P2.

Fonte: Os autores

Assim como foi observado nas respostas de $\mathrm{P} 1$, as de $\mathrm{P} 2$ trouxeram indícios do conhecimento pedagógico (PK) com predominância. Foram 20 excertos em que esse conhecimento se evidenciou, superando a soma dos excertos que caracterizam as outras categorias encontradas, ou seja, conhecimento do conteúdo ( $\mathrm{CK}$ ), conhecimento pedagógico do conteúdo (PCK) e manifestações de mudança de pensamentos ou posturas (MP).

A partir dos relatos do professor P2 (Quadro 5), observa-se que o conhecimento pedagógico para este professor se caracteriza pelos conhecimentos sobre técnicas ou métodos utilizados em sala de aula e uma compreensão de como os estudantes constroem os conhecimentos e adquirem habilidades, bem como a natureza das necessidades e preferências dos estudantes, e estratégias para avaliar a compreensão dos alunos (E-29, E-42 e E-43).

0 conhecimento pedagógico para P2 (assim como no caso de P1), também, caracteriza-se pela prática de ensino e a aprendizagem relacionada à implementação de instruções aos estudantes, planejamento e o gerenciamento da sala de aula em geral (basta retomar E-42 e E-43).
As percepções e as reflexões de P2 giram em torno da execução das atividades, o monitoramento e orientação dos estudantes no desenvolvimento das atividades propostas. Chama a atenção o grande número de excertos relacionados a esse conhecimento (PK) em relação ao número de excertos de CK (4 excertos) e PCK ( 2 excertos), conhecimento do conteúdo e conhecimento pedagógico do conteúdo respectivamente. 0 conhecimento do conteúdo (CK) foi manifestado por P2 nos excertos E-26, E-27, E-28 e E-36. Para P2, esse saber revelou-se, principalmente, no que diz respeito às concepções da natureza do conhecimento (E-26 a E-28), envolvendo a natureza e aos significados dos conhecimentos.

Outro ponto que se observou foram indícios de conhecimento e visões dos conceitos, ideias, e estruturas organizacionais (E-36). Novamente, assim como temos em P1, das falas de P2 emergiram o conhecimento pedagógico do conteúdo, $\mathrm{PCK}$, considerado por muitos autores como o conhecimento principal para uma efetiva prática do professor em sala de aula.

As evidências do PCK, manifestadas a partir dos relatos de P2, relacionavam-se com a capacidade de explorar maneiras alternativas de olhar para mesma ideia e a conscientização sobre o conhecimento prévio dos estudantes (E-30 e E-33).

As manifestações de mudança de pensamentos e posturas em relação à sua prática pedagógica foram outros destaques que emergiram nos relatos de P2 e estão apresentados nos excertos E-38 e E-40. Com relação a esta categoria, ficaram explícitas as mudanças a respeito de sua visão da própria disciplina de Ciências e com relação à sua própria formação.

Em termos gerais, P2 manifestou, predominantemente, relações com o conteúdo pedagógico e apresentou em suas falas poucos excertos relacionados com o conhecimento do conteúdo e conhecimento pedagógico do conteúdo (PCK), em relação aos excertos que evidenciaram o conhecimento pedagógico PK. As evidências de manifestações de mudança de 
pensamentos ou postura sobre sua prática pedagógica não foram tão perceptíveis quanto às observadas nas falas de P1.

Para finalizar, explicitamos algumas conclusões a que chegamos ao final deste processo investigativo.

\section{Considerações conclusivas}

Para concluir e apresentar as principais considerações sobre esta pesquisa retomamos nossas questões primárias e secundárias de investigação. A questão primária tem como indagação: de que maneira uma proposta de formação de professores para o ensino de Ciências por investigação pode promover a iniciação científica dos estudantes? As secundárias são: 1) Quais indícios dos saberes ou conhecimentos docentes de Shulman são manifestados pelos professores a partir dos seus depoimentos sobre suas percepções e reflexões das atividades desenvolvidas com base no ensino de Ciências por investigação? 2) Quais as manifestações de mudança de pensamento ou posturas dos professores a respeito de suas ações em sala de aula são evidenciadas a partir de suas falas sobre as atividades desenvolvidas fundamentadas no ensino de Ciências por investigação?

A partir das percepções dos professores P1 e P2 e, também, dos pressupostos do ensino de Ciências por investigação e da formação docente, intui-se que foi possibilitado aos alunos que buscarem respostas a partir de problemas relevantes e discutirem os resultados encontrados, realizando assim a elaboração e a sistematização do conhecimento científico, isto é, vivenciando a iniciação científica.

Outra proposição pautada nas falas e nos pressupostos teóricos que fundamentam esta pesquisa é a de que a formação continuada em serviço com ênfase nas estratégias de ensino tende a ser mais efetiva quanto ao aprimoramento profissional, tendo em vista satisfazer as preocupações e os anseios dos professores expostos aos desafios da prática pedagógica. Desse modo, ao passo em que consiste em um caminho favorável para a compreensão das etapas do desenvolvimento das atividades investigativas, viabiliza a iniciação científica nos anos iniciais do Ensino Fundamental.

Por meio da Proposta para o desenvolvimento de sequências investigativas em Ciências, evidencia-se, a partir das falas de P1 e P2, que foi possível aos professores aprimorarem os saberes de Shulman (CK, PK e PCK) para execução das ações em sala de aula e desenvolverem as atividades investigativas, acarretando aos alunos o contato com a iniciação científica. Assim, pelos relatos dos professores, cons- tatamos que os estudantes compreenderam o que é realizar uma pesquisa, tornaram-se mais ativos na busca de informações, aprimoraram o trabalho em grupo, demonstrando-se engajados com as situações vivenciadas e tornaram-se mais críticos.

Quanto às questões secundárias formuladas, pode-se perceber que a partir dos relatos dos professores $\mathrm{P} 1$ e P2, encontramos indícios dos três conhecimentos-bases de Shulman que são considerados como o núcleo do conhecimento profissional dos professores (CK, PK e PCK). O conhecimento predominante que emergiu das falas dos professores é o conhecimento pedagógico PK. Foram também encontrados indícios dos conhecimentos do conteúdo $\mathrm{CK} \mathrm{e}$ do conhecimento pedagógico do conteúdo. Indícios de manifestações de mudança de pensamentos ou posturas também emergiram das falas de P1 e P2. Observa-se que os fragmentos de falas (excertos) que expressam o conhecimento pedagógico PK em P2 possuem mais incidências, comparado com P1. Por outro lado, o conhecimento considerado primordial para a atuação do professor em sala e aula, ou seja, conhecimento pedagógico do conteúdo PCK, apresenta maior incidência nas falas de P1 em comparação a P2. Poucos excertos que se referem ao conhecimento do conteúdo são evidenciados, tanto em P1 quanto em P2.

Outro ponto interessante que emerge das falas foram os indícios de manifestações de mudança de pensamentos e posturas em relação à sua prática pedagógica, principalmente a partir dos relatos de P1. Nesta categoria as falas de P1 manifestam mudanças a respeito de sua visão do desenvolvimento das atividades, saindo de uma condição de inércia para uma busca de conhecimento, novos instrumentos e abordagens a serem usadas em sala de aula (E-8). Assim como sua postura na condução das atividades em sala de aula, no qual busca superar as suas barreiras com respeito a proporcionar maior autonomia aos estudantes. Estas manifestações de mudança em relação a pensamentos e posturas não são tão evidentes em P2, como se observa em P1. 0 relato de P2 refere-se à mudança de visão em relação à própria disciplina de Ciências.

Por fim, consideramos a manifestação de evidências de que a aplicação desta Proposta para o desenvolvimento de sequência investigativa em Ciências com professores dos anos iniciais do Ensino Fundamental representou uma contribuição para o desenvolvimento das atividades investigativas em Ciências, proporcionando aos estudantes momentos de iniciação científica, bem como ampliação dos conhecimentos profissionais (Shulman) dos professores participantes. 


\section{Referências}

Alake-Tuenter, E., Biemans, H. J. A., Tobi, H., Wals, A. E. J. e Mulder, M. (2013). Inquiry-based science teaching competence of primary school teachers: A Delphi study. Teaching and Teacher Education, 35, 13-24.

Alake-Tuenter, E., Biemans, H. J. A., Tobi, H., Wals, A. E. J., Oosterheert, I. e Mulder, M. (2012). Inquiry-Based Science Education Competencies of Primary School Teachers: A literature study and critical review of the American National Science Education Standards, International Journal of Science Education, 34(17), 2609-2640.

Araújo, T. B. (2017). Aulas de Ciências: Uso e desenvolvimento de sequências investigativas [Dissertação de Mestrado. Universidade Tecnológica Federal do Paraná].

Arce, A., Silva, D. A. S. e Varotto, M. (2011). Ensinando Ciências na Educação Infantil. Editora Alínea.

Azevedo, M. C. S. (2013). Ensino por investigação: problematizando as atividades em sala de aula. Em Carvalho, A. M. P. (Org.). Ensino de ciências: unindo a pesquisa e a prática (pp. 19-33). Cengage Learning.

Bardin, L. (2011). Análise de conteúdo. Edições 70.

Bogdan, R. e Biklen, S. (1994). Investigação qualitativa em educação: uma introdução à teoria e aos métodos. Portugal: Porto Editora.

Campos, M. C. C. e Nigro, R. G. (1999). Didática de ciências: o ensino-aprendizagem como investigação. FTD.

Carvalho, A. M. P. (2013). Ensino de Ciências por investigação: condições para implementação em sala de aula. Cengage Learning.

Cunha, A. M. O. e Krasilchik, M. (2000). A formação continuada de professores de Ciências: percepções a partir de uma experiência. Anais da Reunião da Associação Nacional de Pós-Graduação e Pesquisa em Educação (Anped), 23 (pp. 1-14). Caxambu.

Dobber, M., Zwart, R., Tanis, M. e Oers, B. V. (2017). Literature review: The role the teachers in inquiry-based education. Educational Research Review, 22, 194-214.

Garcia, M. (1997). A formação de professores: novas perspectivas baseadas na investigação sobre o pensamento do professor. Em A. Nóvoa (Coord.), Os professores e a sua formação (51-76). Publicações Dom Quixote.

Gil-Pérez, D. (1996). Orientações didáticas para a formação continuada de professores de Ciências. Em: L. C. Menezes (Org.), Formação Continuada de Professores de Ciências no âmbito ibero-americano. Autores Associados NUPES.

Grossman, P. L. (1990). The making of a teacher: Teacher knowledge and teacher education. Teacher College Press.
Harris, J. B., Mishra, P. e Koehler, M. J. (2009). Teacher's Technological Pedagogical Content Knowledge and learning activity types: curriculum-based technology integration Reframed. Journal of Research on Technology in Education, 41(4), 393-416.

Kirschner, S., Borowski, A., Fischer, H. E., Gess-Newsome, J. e von Aufschnaiter, C. (2016). Developing and evaluating a paperand-pencil test to assess components of physics teachers' pedagogical content knowledge. International Journal of Science Education, 38(8), 1343-1372.

Kleickmann, T., Richter, D., Kunter, M., Elsner, J., Besser, M., Krauss, S. e Baumert, J. (2013). Teachers' content knowledge and pedagogical content knowledge: The role of structural differences in teacher education. Journal of Teacher Education, 64(1), 90-106.

Lei n. 9394, de 20 de dezembro de 1996 (1996). Estabelece as diretrizes e bases da educação nacional. Diário Oficial da União. Ministério da Educação.

Lei n. 13.005, de 25 de junho de 2014 (2014). Aprova o Plano Nacional de Educação - PNE e dá outras providências. Diário Oficial da União. Presidência da República/Casa Civil/Subchefia para Assuntos Jurídicos.

Lüdke, M. e André, M. E. D. A. (2013). Pesquisa em Educação: abordagens qualitativas (2a ed.). EPU.

Maués, E. e Lima, M. E. C. C. (2006). Atividades investigativas nas séries iniciais. Revista Presença Pedagógica, 12(72), 34-43.

Ministério da Educação (2017). Base Nacional Comum Curricular. Autor.

Next Generation Science Standards (2013). Next generation science standards: For states, by states. National Academies Press.

National Research Council (1996). National science education standards. National Academy Press.

National Research Council (2000). Inquiry and the national science education standards: A guide for teaching and learning. National Academies Press.

National Research Council (2012). A framework for K-12 science education: Practices, crosscutting concepts, and core ideas. National Academies Press.

National Research Council (2015). Inquiry: Thoughts, Views, and Strategies for the K-5 Classroom. National Academies Press.

Resolução no 02, de 01 de julho de 2015 (2015). Define as Diretrizes Curriculares Nacionais para a formação inicial em nível superior (cursos de licenciatura, cursos de formação pedagógica para graduados e cursos de 
segunda licenciatura) e para a formação continuada. Conselho Nacional de Educação. Ministério da Educação, Conselho Nacional de Educação, Conselho Pleno.

Sá, E. F., Paula, H. F., Lima, M. E. C. C. e Aguiar, O. G. (2007). As características das atividades investigativas segundo tutores e coordenadores de um curso especialização em ensino de ciências. Anais do Encontro Nacional de Pesquisa em Educação em Ciências (VI ENPEC), Rio de Janeiro, 6.

Sasseron, L. H. (2015). Alfabetização científica, ensino por investigação e argumentação: relações entre ciências da natureza e escola. Revista Ensaio, 17 (especial), 49-67.

Sasseron, L. H. (2018). Ensino de Ciências por Investigação e o Desenvolvimento de Práticas: Uma Mirada para a Base Nacional Comum Curricular. Revista Brasileira de Educação em Ciências, 18(3), 1061-1085.

Sasseron, L. H. e Duschl, R. A. (2016). Ensino de Ciências e as práticas epistêmicas: o papel do professor e o engajamento dos estudantes. Investigações em Ensino de Ciências, 21(2), 52-67.

Schön, D. A. (1992). La formación de profesionales reflexivos. Paidos.

Shulman, L. S. (1986). Those who understand: Knowledge growth in teaching. Educational Researcher, 15(2), 4-14.

Shulman, L. S. (1987). Knowledge and teaching: Foundations of the new reform. Harvard Educational Review, 57(1), 1-22.
Silva, V. F. e Bastos, F. (2012). Formação de Professores de Ciências: reflexões sobre a formação continuada. Alexandria Revista de Educação em Ciência e Tecnologia, 5(2), 150-188.

Sorge, S., Keller, M. M., Neumann, K. e Möller, J. (2019). Investigating the relationship between pre-service physics teachers' professional knowledge, self-concept, and interest. Journal of Research in Science Teaching, 56(7), 937-955.

Tardif, M. (2002). Saberes docentes e formação profissional. Vozes.

Van Driel, J. H., Berry, A. e Meirink, J. (2014). Research on science teacher knowledge. Em N. G. Lederman e S. K. Abell (Eds.), Handbook of research on science education (pp. 848-870). Routledge.

Vieira, F. A. C. (2012). Ensino por Investigação e Aprendizagem Significativa Crítica: análise fenomenológica do potencial de uma proposta de ensino. [Tese de Doutorado, Universidade Estadual Paulista].

Yang, Y., Liu, X. e Gardella Jr., J. A. (2018). Effects of Professional Development on Teacher Pedagogical Content Knowledge, Inquiry Teaching Practices, and Student Understanding of Interdisciplinary Science, Journal of Science Teacher Education, 29(4), 263-282.

Zômpero, A. F. e Laburú, C. E. (2011). Atividades investigativas no ensino de ciências: aspectos históricos e diferentes abordagens. Revista Ensaio, 13(3), 67-80. 